\title{
ENTRE DISCURSOS E PRÁTICAS: ROTINA MULTIMÍDIA EM EMPRESAS JORNALÍSTICAS
}

\author{
Between speeches and practices: multimedia routine in journalistic companies
}

Entre discursos y prácticas: rutina multimedia en empresas periodísticas

Alexandre Lenzi

Universidade Federal de Mato Grosso do Sul (UFMS)

lenzi.alexandre@gmail.com

\begin{abstract}
Resumo
A necessidade de uma prática multimídia na rotina de produção de conteúdo jornalístico para sites noticiosos é reconhecida por gestores e lideranças de redações. Neste artigo, busca-se refletir sobre tal cenário a partir da perspectiva de três empresas brasileiras: Folha de $S$. Paulo, $O$ Globo e Gazeta do Povo. Para isso, recorre-se ao resgate dos discursos oficiais destas empresas em relação às mudanças recentes em suas rotinas de produção e à análise de uma amostra do que é produzido e publicado diariamente em seus sites. Como parte da metodologia, é realizada observação de análise de conteúdo a partir da seleção de reportagens dos três jornais durante uma semana construída. Como resultado, percebe-se que embora avançando, em especial na grande reportagem, a rotina multimídia não está tão incorporada na prática como já está no discurso.
\end{abstract}

Palavras-chave: Jornalismo on-line. Reportagem multimídia. Palavra-chave. Rotinas de produção.

\begin{abstract}
The need for a multimedia practice in the production routine of journalistic content to websites is recognized by managers and leaders of media companies. In this article, the reflection is about three Brazilian newspapers: Folha de S. Paulo, O Globo and Gazeta do Povo. The study includes the review of the official discourse in relation of recent routines changes in these companies and the analysis of examples of what is produced and published daily on their websites. As a result, here it is possible to realize that the routine multimedia is incorporated more in the discourse that in the practice.
\end{abstract}

Key words: Online journalism. Multimedia report. Production routines.

\section{Resumen}

La necesidad de una práctica multimedia en la rutina de producción de contenido periodístico para sitios noticiosos es reconocida por gestores y líderes de periódicos. En este artículo, se busca reflexionar sobre tal escenario desde la perspectiva de tres empresas brasileñas: Folha de S. Paulo, O Globo y Gazeta do Povo. Para ello, se recurre al rescate de los discursos oficiales de estas empresas en relación a los cambios recientes en sus rutinas de producción y al análisis de una muestra de lo que es producido y publicado diariamente en sus sitios. Como resultado, se percibe que, aunque avanzando, la rutina multimedia no está tan incorporada en la práctica como ya está en el discurso.

Palabras clave: Periodismo online. Reportaje multimedia. Rutinas de producción. 


\section{INTRODUÇÃO}

Produzir conteúdos noticiosos em formatos multimídia é uma demanda consolidada no discurso dos gestores de empresas jornalísticas que abastecem versões on-line. Este artigo busca testar até que ponto o mesmo discurso teórico institucional avança para a prática informativa no dia a dia. Esta é a questão-problema que guia o trabalho. Para isso, por meio do monitoramento por análise de conteúdo de reportagens dos sites de três jornais brasileiros (Folha de S. Paulo, O Globo e Gazeta do Povo), no período de uma semana construída, coleta-se uma amostra que permite avaliar a diversificação dos recursos multimídia na produção jornalística de rotina.

Na busca pela multimidialização do jornalismo on-line ${ }^{1}$, é preciso reconhecer que já vivenciamos mais de 20 anos de experimentação e testes em redações mundo afora, inicialmente replicando no meio on-line o que se fazia em outras plataformas. No começo, a internet era, sobretudo, um canal a mais para divulgar o que jornais impressos, emissoras de rádio e de TV produziam para seus veículos de origem. Mas aos poucos, diante dos recursos que só a rede oferece e trabalhando com técnicas em constante modernização, passou-se produzir conteúdo jornalístico pensado especificamente para o ambiente on-line, aproveitando características como, por exemplo, a hipertextualidade e o novo alcance proporcionado, a multimidialidade como integração de diferentes recursos em um mesmo produto informativo, e a interatividade como uma nova forma de se relacionar com o público consumidor. E é justamente no processo de multimidialização da produção jornalística que surge uma série de desafios, diante da proposta de promover uma real integração entre diferentes conteúdos apresentados em distintos formatos.

Em sua essência, entendida como a utilização de duas ou mais mídias na mesma produção informativa, a prática multimídia não é exclusividade do ambiente on-line. No impresso, ao usar texto, infográfico e fotos para noticiar o mesmo fato, já temos uma prática multimídia. Na TV tradicional, imagens e áudios também se complementam. No ambiente on-

\footnotetext{
${ }^{1}$ Aqui o termo jornalismo on-line aparece como sinônimo de jornalismo digital, por respeitar nomenclatura utilizada pelos próprios jornais. No meio acadêmico, Salaverría (2019) lembra que durante as últimas décadas o termo jornalismo on-line foi o mais usado, sendo, no entanto, substituído no cenário mais recente pelo conceito de jornalismo digital, hoje imperante. Há, ainda, outras vertentes, que preferem uma especificação maior, adotando termos como ciberjornalismo ou ainda webjornalismo.
} 
line, todos os recursos estão lá, mas com o diferencial de que a condução da leitura é feita pelo usuário, criando um novo padrão de interatividade. Usando uma metáfora de Javier Díaz Noci (2001), na multimidialidade, $1+1+1$ soma algo mais do que 3 .

Steve Hill e Paul Lashmar (2014), em seu guia para o jornalismo on-line, apontam a característica multimídia como uma das principais vantagens da divulgação de notícias na internet, no sentido de poder fornecer uma variedade de conteúdo em textos, áudios e vídeos, que podem ser facilmente atualizados ao longo do dia. Os autores entendem que, entre as implicações de uma mentalidade multimídia, está a necessidade de entender mais sobre programação e de exigir profissionais mais flexíveis na forma como trabalham.

É interessante observar que apesar das inovações da produção jornalística multimídia, o texto ainda tende a aparecer como elemento principal, fio condutor para as demais peças e recurso básico para introduzir e contextualizar o tema. O termo longform tem sido aplicado para narrativas onde textos longos e aprofundados são o grande atrativo. Mas outros elementos além do texto, mesmo quando não protagonistas da peça informativa, têm papel representativo na narrativa on-line (LONGHI, 2014).

Ao estudar a característica da multimidialidade, Salaverría (in CANAVILHAS, 2014) chama a atenção para a importância da integração eficiente entre os diferentes elementos: o texto, o som, as imagens e o vídeo, assim como outros que possam surgir no futuro, devem estar devidamente coordenados para que o resultado seja harmonioso, mesmo sendo essa uma tarefa mais complicada do que parece. $\mathrm{O}$ autor espanhol indica alguns critérios que facilitam a coordenação de elementos multimídia na composição do material informativo.

São eles: 1) compatibilidade (usar elementos cujo seguimento simultâneo possa ser realizado sem esforço para o público em geral, sem que exista uma competição pela atenção do internauta que acabe dispersando-o), 2) complementaridade (união de elementos que se enriqueçam mutuamente), 3) ausência de redundância (um certo grau de repetição é aceitável e até desejável, mas a excessiva redundância aborrece o público), 4) hierarquização (determinar qual é a linguagem que melhor se adequa à transmissão de cada peça do conteúdo), 5) ponderação (para limitações, como tempo, espaço, velocidade da internet, entre outras) e 6) adaptação (respeito básico à plataforma on-line, com uso de tipografias, cores e dimensões espaciais próprias do meio). 


\section{PRIORIZAÇÃO DO ON-LINE}

Com o reconhecimento do potencial do jornalismo on-line mais evidente nos últimos anos, começou-se a se desenhar o processo de inversão de papel (LENZI, 2018), no sentido de marcas de jornais impressos passarem a priorizar a produção de conteúdo on-line em suas rotinas. A exemplo do que aconteceu mundo a fora (NEGREDO e SALAVERRÍA, 2009), o final da década de 2010 foi marcado por grandes mudanças das redações de jornais brasileiros, com experimentações práticas da convergência entre as equipes do impresso e do on-line. Processo intensificado nesta última década, diante de um cenário de constante mudanças (ANDERSON et al, 2013; COSTA, 2014).

Concorrentes diretos no mercado brasileiro, os jornais $O$ Estado de S. Paulo e Folha de S. Paulo, por exemplo, apresentaram movimentos semelhantes ao longo da migração de suas marcas de origem impressa para a plataforma digital, sendo o ano de 2010 o mais significativo para os dois em suas trajetórias recentes no caminho à priorização do on-line. No caso da Folha, foi o ano do processo que a empresa chamou de "fusão orgânica" entre o jornal impresso e a versão on-line (LENZI, 2018).

Alguns anos depois, em setembro de 2016, a Folha se anunciou como o primeiro jornal brasileiro a ter circulação digital maior do que a impressa. Segundo dados da própria empresa, a edição digital alcançou, em agosto daquele ano, mais de metade do total. Citando números do Instituto Verificador de Comunicação (IVC), a Folha informa que dos 316,5 mil exemplares de média diária no mês, 161,8 mil ou $51 \%$ foram relativos à edição digital do jornal, contra 154,7 mil (49\%) da impressa (FOLHA DE S. PAULO, 2016). O desafio, então, passou a ser transformar uma parcela maior de leitores digitais em leitores pagantes. Vale lembrar que desde janeiro de 2012 a Folha adota o modelo de paywall flexível, quando o acesso gratuito ao conteúdo do site se limitou a um determinado número de textos por mês. Para ler mais, é preciso fazer uma assinatura. Em lançamento de novo projeto editorial em março de 2017, a empresa ressalta que a versão impressa continua a responder pela maior parte da receita publicitária e que a Folha considera que a garantia da qualidade jornalística está na remuneração adequada do trabalho investido, que os direitos autorais precisam ser preservados e que a pirataria deve ser combatida.

No cenário brasileiro contemporâneo, no entanto, entre as mudanças mais expressivas e mais recentes, ganham destaque as que ocorreram na redação do $O$ Globo, no Rio de Janeiro, o que incluiu até mesmo a mudança de sede em janeiro de 2017, com uma 
organização física pensada para um novo fluxo de produção de notícias. Fundado em 1925, o jornal faz parte do grupo homônimo, que era até então o maior conglomerado de mídia da América Latina. Ao longo das últimas décadas, $O$ Globo teve presença como protagonista no processo de levar as marcas de jornais impressos brasileiros para a internet. Lançou a primeira versão do seu site ainda em 1996, mais precisamente no dia 29 de julho daquele ano. Dez anos mais tarde, em 2006, passou a oferecer uma versão digital do jornal, com a reprodução das páginas da edição impressa. Transformação mais profunda ocorreu em novembro de 2009, quando as redações do jornal e do site, que até então trabalhavam de forma integrada apenas virtualmente, passaram a ocupar o mesmo espaço físico. Com isso, os mesmos profissionais, a exemplo de repórteres e editores, passaram a atender simultaneamente as demandas do jornal impresso e da versão on-line.

Um novo processo de mudança teve início em março de 2014, no sentido de priorizar cada vez mais o conteúdo on-line. Desde então, os editores de área iniciam o trabalho na redação às $7 \mathrm{~h}$, coordenando a produção das equipes de acordo com as características de cada um dos canais de publicação: site, celular, tablet e impresso. As notícias, publicadas nos meios digitais, são complementadas ao longo do dia, em um processo chamado pela empresa de edição contínua.

Em reportagem anunciando a unificação em 2017 da redação de $O$ Globo com outros dois jornais do grupo, Extra e Expresso, para produção de conteúdo multimídia em diferentes plataformas, a mudança daquele ano é apresentada como a maior transformação digital de uma publicação jornalística do país (O GLOBO, 2017). A proposta de revisar a estrutura e os processos de trabalho é apontada como estratégia para ampliar o foco nos ambientes digitais, especialmente por meio de smartphones, prometendo que, durante todo o dia, as principais notícias serão aprofundadas e enriquecidas com análises, vídeos e infográficos em tempo real. E para o impresso, o diferencial indicado é um conteúdo analítico e reportagens especiais.

Outro exemplo concreto de priorização do on-line no cenário brasileiro foi deflagrado no dia $1^{\circ}$ de junho de 2017, quando o então quase centenário jornal paranaense Gazeta do Povo deixou de publicar edições diárias da versão impressa. A página on-line continuou a ter conteúdo jornalístico atualizado diariamente, e uma versão em papel passou a ser publicada somente aos sábados, em formato de revista, com proposta mais analítica e contextual. A empresa fechou seu parque gráfico e passou a terceirizar a impressão da edição semanal, que tem circulação apenas na região metropolitana da capital Curitiba. A mudança representou um direcionamento estratégico, comercial e editorial do grupo, focado em conteúdo digital, em 
especial para dispositivos móveis, como smartphones e tablets, dentro do conceito mobile first. Fundada em 1919, a Gazeta do Povo faz parte do Grupo Paranaense de Comunicação (GRPCom), conglomerado multimídia regional que também conta com emissoras de rádio e televisão. Presente na internet desde a década de 1990, o jornal já fez reformulações do site nas últimas décadas, mas nada comparado com a transformação mais recente (LENZI, 2018).

A empresa informa que passará a oferecer dezenas de novos produtos jornalísticos distribuídos pelas plataformas diversas e em redes sociais, durante 24 horas, todos os dias (GAZETA DO POVO, 2017). São boletins, vídeos e podcasts distribuídos em uma programação fixa, mas sujeita a alterações diante de conteúdos factuais. Entre os conteúdos, comentários de colunistas e repórteres, serviços como previsão do tempo e programação cultural, e resumos com o noticiário do dia. A organização do trabalho segue uma rotina na qual a primeira reunião de planejamento ocorre às $8 \mathrm{~h} 30$, com a participação dos editores. Às 16h, os editores de todas as áreas voltam a se reunir para realinhar a distribuição do conteúdo do dia. E à 0 h, o editor de homepage deixa pronta a capa do site que vai amanhecer para os leitores e o editor de mídias sociais faz a programação dos posts da madrugada.

Agora, a promessa da empresa, em comunicado institucional, é de que o novo site, tecnologicamente reformulado, utilize o recurso de georreferenciamento para entregar um noticiário direcionado conforme os interesses de seus leitores e o local em que estejam. Ainda segundo a empresa, a nova plataforma foi desenhada buscando também aumentar a velocidade de carregamento dos conteúdos on-line, diminuindo o consumo de dados e facilitando a experiência do leitor. O processo de produção dos conteúdos também foi transformado. A empresa encomendou uma nova plataforma digital que permite que repórteres escrevam e publiquem textos, fotos e vídeos (incluindo transmissões ao vivo) a partir de um aplicativo próprio baixado em seus dispositivos móveis. Ou seja, a notícia é produzida e publicada a partir de smartphones. E o foco é que seja também consumida preferencialmente por smartphones e tablets.

\subsection{Produção multimídia na prática}

Diante deste cenário de mudanças recentes, estas três empresas jornalísticas, Folha de S. Paulo, O Globo e Gazeta do Povo, foram selecionadas para a amostra a ser estudada neste artigo. Mas para ir além do discurso dos gestores, optou-se por olhar para a produção, na tentativa de identificar se tal multimidialização ocorre também na prática. 
Trabalha-se com o conceito de semana construída, de Klaus Krippendorff (1980), no qual a partir de um universo amplo de dados é selecionada uma pequena amostra que é organizada de forma a ser representativa do conjunto total. Dentro desta proposta, pega-se o domingo da primeira semana, a segunda-feira da segunda semana e assim sucessivamente até ter uma semana completa. A data de início foi escolhida de forma aleatória, sendo que, para este monitoramento, a coleta ocorreu entre 14 de janeiro e 3 de março de 2018. Em cada um dos sete dias, sempre entre $8 \mathrm{~h}$ e $9 \mathrm{~h}$, foram selecionadas duas matérias de cada veículo, sendo uma a manchete e outra a reportagem com foto principal no site. Desta forma, somaram-se 14 matérias em cada um cada um dos três sites, totalizando 42 reportagens analisadas.

Na divisão do material coletado por editorias, destaque para Política, com 20 matérias; seguido por Cotidiano/Geral, com oito; Economia com sete; Cultura com três; Gastronomia com duas; Esportes com uma; e Mundo com uma.

Como recurso rotineiro, as matérias apresentam textos, fotos ou ilustrações e hiperlinks para matérias de edições anteriores, nas diferentes editorias. Infográficos também aparecem no noticiário factual, mas ainda em menor quantidade. Em relação aos temas, o uso de infográfico é identificado principalmente nas editorias de Economia e Política. E, por fim, recursos como vídeo e áudios foram os menos encontrados como elementos de rotina nas plataformas digitais, sendo usados principalmente em matérias também das editorias de Economia e Política, assim como ocorre com os infográficos.

Na Folha de S. Paulo, das 14 matérias analisadas, além do texto e das fotos, pelo menos cinco traziam também infográficos e uma apresentava conteúdo em vídeo. Entre os infográficos, há registros de modelos tradicionais, que nada se diferenciam daqueles publicados na versão impressa, mas há também modelos interativos, pensados para o ambiente on-line. Merece ser destacado, como exemplo deste último grupo, o infográfico sobre o número de policiais militares atuantes no Rio de Janeiro, publicado na sexta-feira, 23 de fevereiro, na reportagem "Após promoções sem concurso, PM do Rio tem mais chefes que soldados", da editoria Cotidiano (Figura 1).

Vale citar, ainda, que entre o material fotográfico, o recurso da galeria de imagens aparece ao menos quatro vezes na Folha de S. Paulo, como na reportagem “Onda do chá volta, forma sommeliers e leva a reinvenção de produtores de SP” (Figura 2), publicada no domingo, 14 de janeiro, na editoria Cotidiano. 
Figura 1 - Detalhe de infográfico interativo da Folha de S. Paulo

\section{POR QUE O RIO TEM TANTOS SARGENTOS?}

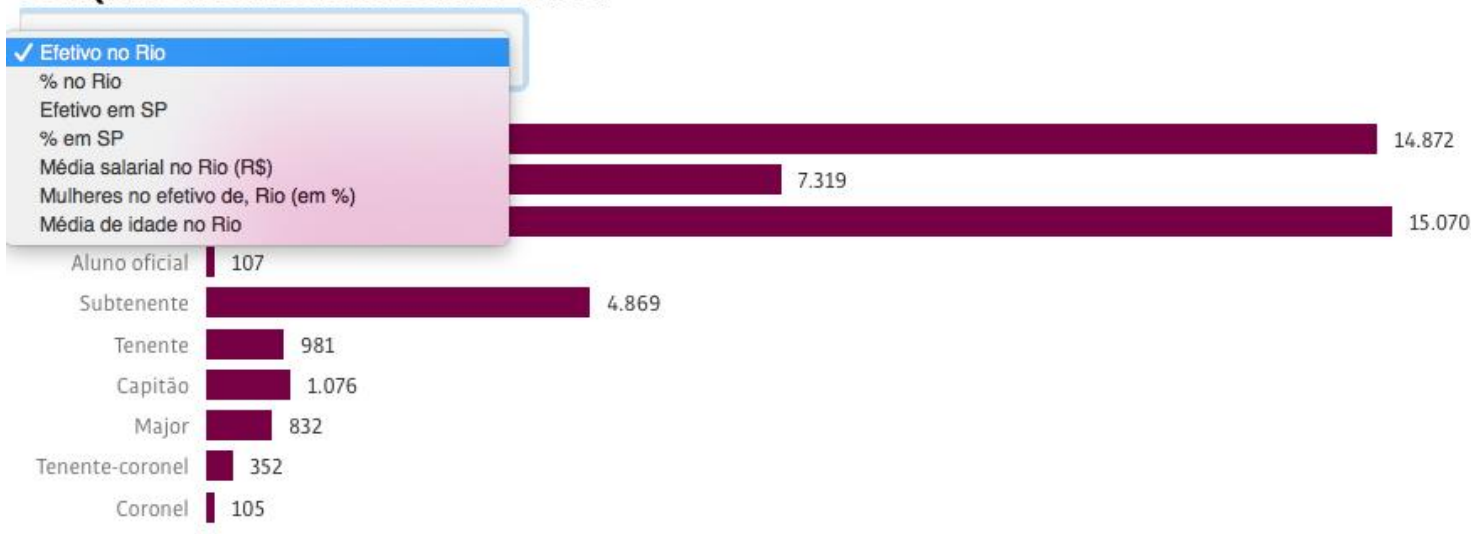

Total no Rio: 45.583

Total em São Paulo: 84.422

1 - Em 1996, praças passaram a ser promovidos só por tempo de serviço; em SP, promoção depende de concurso

2- 0 soldado era promovido para cabo após 10 anos de serviço e, com 15, se tornava sargento

3 - Em 2012, uma alteração legislativa reduziu esse período para 6 e 12 anos, respectivamente

No Estado faltam $\mathbf{2 2 . 4 1 0}$ soldados

Mas sobram $\mathbf{8 . 0 8 6}$ sargentos

Fonte: Polícia Militar do Estado do Rio de Janeiro

Fonte: captura de tela feita pelo autor. Disponível em: <https://www1.folha.uol.com.br/cotidiano/2018/02/apospromocoes-sem-concurso-pm-do-rio-tem-mais-chefes-que-soldados.shtml>, publicado e visitado em 23/02/2018.

Figura 2 - Detalhe de galeria de fotos da Folha de S. Paulo

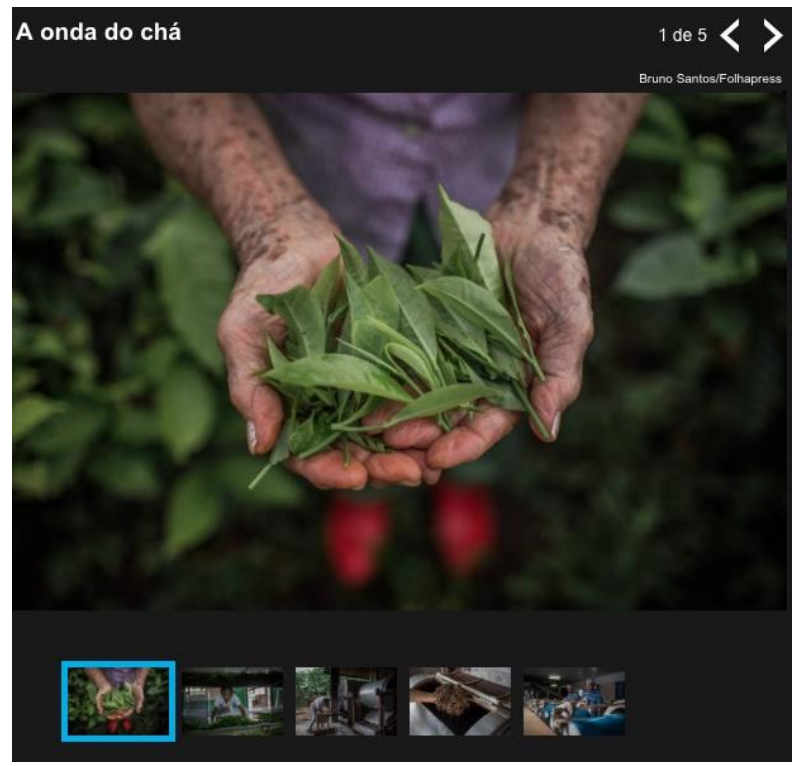

Fonte: Captura de tela feita pelo autor. Disponível em:

<https://www1.folha.uol.com.br/cotidiano/2018/01/1950341-onda-do-cha-volta-forma-sommeliers-e-leva-areinvencao-de-produtores-de-sp.shtml>, publicado e visitado em 14/01/2018. 
O uso do vídeo aparece em uma única matéria, uma reportagem da editoria de turismo, "Caminho dos Diamantes revela igrejas e casarios coloniais na Estrada Real”, publicada no sábado, 3 de março. $\mathrm{O}$ vídeo em questão consiste em uma edição de imagens, com música de fundo e sem entrevista, com duração de dois minutos e nove segundos. Na mesma matéria, além do vídeo, há a reportagem em texto, fotos (duas destacadas na matéria e outras oito em uma galeria em slideshow) e um infográfico, com o mapa da localização da estrada turística.

No $O$ Globo, texto, fotos ou ilustrações e os tradicionais hiperlinks também se fazem presentes. Mas entre as 14 matérias analisadas, entende-se que ao menos duas ganham destaque podendo ser enquadradas como grandes reportagens multimídia.

Já no primeiro dia de coleta, domingo, 14 de janeiro, o jornal carioca traz um conteúdo especial multimídia sobre assédio no ambiente de trabalho na editoria de Economia. A produção "Assédio no trabalho dificulta ascensão de mulheres nas empresas" disponibiliza textos, fotos, ilustrações, infográfico, vídeo e áudio com depoimentos e relatos (Figura 3).

E na semana seguinte, na segunda-feira, 22 de janeiro, outro especial ganha destaque no site: "Odorico Paraguaçu completa 45 anos e segue atual na política brasileira", reportagem que faz referência ao personagem da novela $\mathrm{O}$ Bem-Amado. Este trabalho diferencia-se pelo uso de ilustrações, incluindo em um infográfico que compara o personagem com políticos reais do cenário contemporâneo (Figura 4). A reportagem traz, ainda, um vídeo com 10 minutos de duração, apresentando trechos da novela O Bem-Amado e de discursos de políticos do cenário atual, intercalados com depoimentos com análises de especialistas.

Figura 3 - Frame de vídeo em reportagem do $O$ Globo

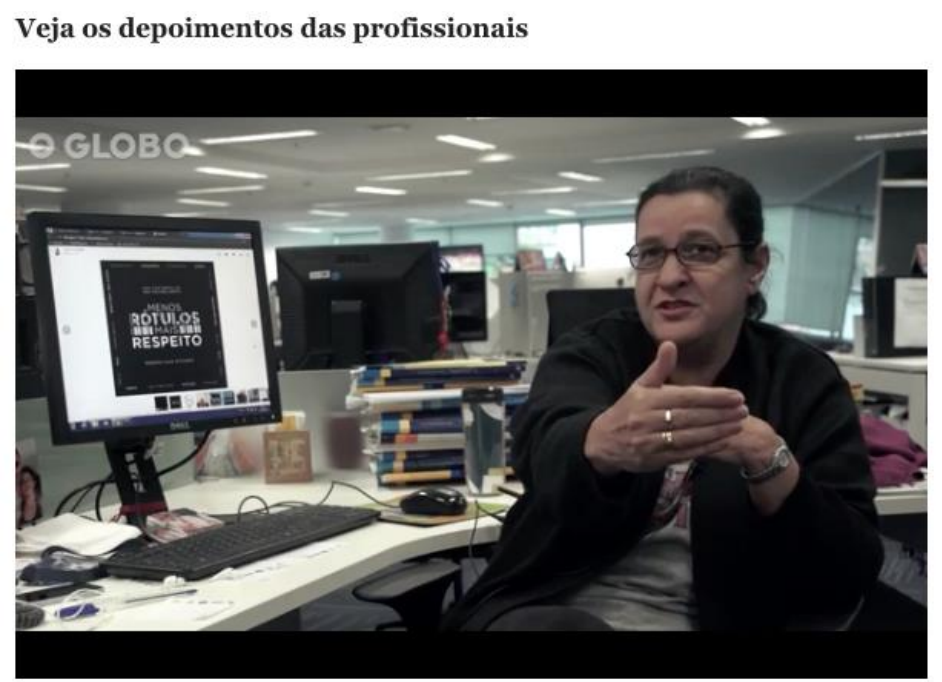

Fonte: Captura de tela feita pelo autor. Disponível em: <https://oglobo.globo.com/economia/assedio-no-trabalhodificulta-ascensao-de-mulheres-nas-empresas-22285265>, publicado e visitado em 14/01/2018. 
Figura 4 - Detalhe de infográfico com ilustração de $O$ Globo

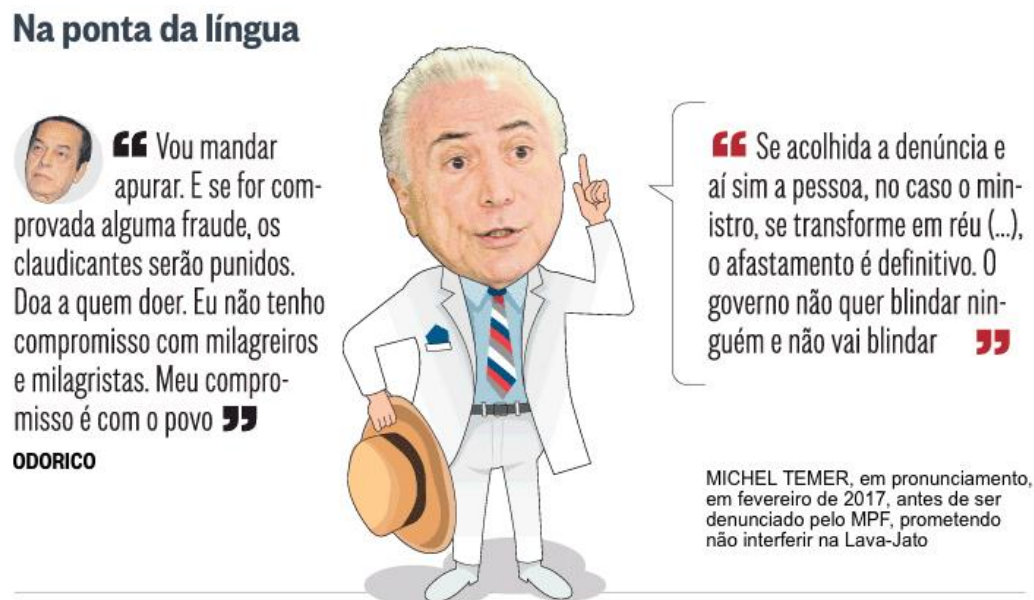

Fonte: Captura de tela feita pelo autor. Disponível em: <https://oglobo.globo.com/brasil/odorico-paraguacucompleta-45-anos-segue-atual-na-politica-brasileira-22312851>, publicado e visitado em 22/01/2018.

Ao longo das demais coletas em $O$ Globo, mesmo em dias de semana, também aparecem outros conteúdos multimidializados. Por exemplo, a entrevista exclusiva com o então presidente do Tribunal Superior Eleitoral (TSE), Luiz Fux, publicada na quarta-feira, 7 de fevereiro, é disponibilizada em vídeo para os assinantes do jornal.

Por fim, na Gazeta do Povo as publicações analisadas foram as que apresentaram menor variedade de recursos. Além de textos e fotos, das 14 reportagens do jornal paranaense, apenas uma apresentava também um vídeo e uma única outra trazia um infográfico. Vale ressaltar que, no caso do vídeo, nem mesmo era uma produção própria: a matéria "Vídeo de Cristiane Brasil causa mal-estar no Planalto e no próprio partido dela”, publicada na terçafeira, 30 de janeiro, na editoria de Política, trazia apenas a reprodução do vídeo mencionado já no título da notícia. E o uso do infográfico aparece em outra matéria, também na editoria de Política, "União vai retomar rodovias federais no Paraná e conduzir nova licitação do pedágio", publicada no sábado, 3 de março, como um mapa apontado os trechos das rodovias citadas (Figura 5), a exemplo dos que se publicam também no impresso.

Uma observação merece ser levada em consideração: o novo site da Gazeta do Povo trabalha com geolocalização e, como o acesso para esta pesquisa ocorreu fora do estado do Paraná, as matérias destacadas no site tendiam a ser aquelas de conteúdo com maior interesse nacional. Uma amostra coletada no Paraná, com conteúdo mais local, com produção centralizada na equipe paranaense, pode apresentar resultados diferenciados em relação à variedade de recursos multimídia utilizados na narrativa jornalística. 
Figura 5 - Infográfico de Gazeta do Povo

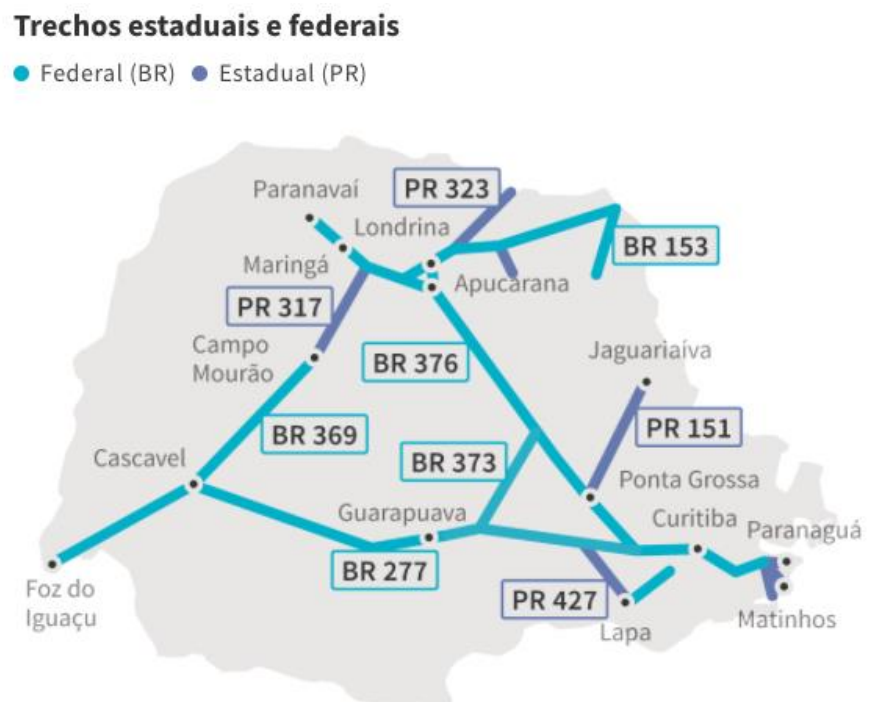

Extensão

O Anel de Integração é composto atualmente de cerca de:

2,5 mil km de rodovias pedagiadas

Fonte: Captura de tela feita pelo autor. Disponível em: <http://www.gazetadopovo.com.br/politica/parana/uniaovai-retomar-rodovias-federais-no-parana-e-conduzir-nova-licitacao-do-pedagio-07i912uxzk7e1xignz07gpg1f >, publicado e visitado em 02/03/2018.

\subsection{Multimídia como trabalho de equipe}

Até um passado bastante recente, quando o assunto era reportagem multimídia, ganhava destaque a imagem do profissional multimídia, o jornalista polivalente, a banda de um homem só, o faz tudo, imagem durante muito tempo vendida como o profissional modelo das redações convergentes. Neste contexto, um mesmo repórter teria a função de apurar a matéria, fazer fotos dos entrevistados ou dos eventos cobertos, produzir e gravar vídeos (quem sabe até editá-los), escrever uma versão resumida da matéria para o site e uma mais completa para o impresso, e comentar o assunto em diferentes canais da empresa, seja em uma transmissão ao vivo nas redes sociais, seja na programação de emissoras de rádio e/ou televisão, no caso de conglomerados multimídia. Em situações extremas, o repórter era responsável também pela edição e publicação da matéria no on-line e pela divulgação da mesma por meio das diferentes redes sociais. Melhor ainda (para a empresa) era se fizesse tudo isso com o mesmo salário de quando era "apenas" um repórter de texto, diante da onipresente necessidade de controlar custos. São pontos que afetam esferas ainda mais 
amplas, como o âmbito legal, questão esta que passa pela necessidade de uma atualização da legislação e de um reforço da fiscalização.

Demorou para que os gestores percebessem que os profissionais, salvo exceções (se é que realmente existe alguma), não conseguiriam atender tamanha demanda. No melhor dos cenários, alguns deram conta de boa parte. Mas, ainda assim, sem manter um padrão de qualidade nas diferentes frentes de produção realizadas quase que simultaneamente. Por exemplo, o repórter fez um bom texto e boas fotos, mas o vídeo ficou tremido e não teve condições de ser publicado.

No cenário contemporâneo, conforme Lenzi (2018), a multitarefa vendida como polivalência começou a perder lugar para uma produção multimídia em equipe, onde um modelo comum é composto, no mínimo, por um repórter mais experiente cuidando da apuração e da produção do texto (para o site, para o impresso e para um potencial infográfico também), acompanhado de um profissional de imagem, que fotografa e filma e, via de regra, também edita o vídeo. E na redação, há o suporte do(s) editor(es) para as respectivas edições para o on-line e para o impresso e da equipe de redes sociais, que distribui a chamada para a matéria de acordo com características próprias de cada canal e dentro de horários previamente planejados. Pelo menos, é este o cenário reconhecido como o ideal, sujeito obviamente a atropelos diante dos frequentes imprevistos que fazem parte das rotinas das empresas jornalísticas.

\section{CONSIDERAÇÕES}

Percebe-se, desta forma, que embora avançando significativamente, a rotina multimídia ainda não está tão incorporada na prática de empresas jornalísticas como já está no discurso dos seus gestores. O potencial da integração dos novos recursos à narrativa é, sim, reconhecido. Mas no dia a dia da produção, a maioria dos trabalhos jornalísticos ainda segue modelos que pouco se diferenciam das versões impressas. Vídeos, áudios, infográficos animados e galerias de fotos, só para citar alguns exemplos, são recursos incorporados à nova rotina, mas ainda não de forma tão frequente quanto os tradicionais textos e fotos que seguem predominantes, acrescidos na maioria dos casos apenas de links para matérias sobre o mesmo assunto já publicadas anteriormente.

Entende-se que um dos grandes desafios das redações jornalísticas contemporâneas é justamente trabalhar a visão multimídia ao longo das diferentes etapas de produção, do 
planejamento até a distribuição. Isto devido ao fato de que a complementariedade entre as informações apresentadas em diferentes formatos é um ponto chave para a prática da grande reportagem multimídia e até mesmo de produções factuais para o jornalismo on-line. Para evitar a redundância exagerada, é essencial trabalhar a visão multimídia já no processo de elaboração da pauta, no planejamento, com o objetivo de identificar que parte da história é melhor ser contada em cada formato, de descobrir como explorar o melhor de cada plataforma para aquela reportagem.

O ideal é pensar em tudo isto antes da apuração, não no sentido de engessar o processo, mas com o objetivo de prever a necessidade de levantamento de informações específicas (mais detalhadas, no caso de infográficos, por exemplo) ou de atentar para detalhes muito direcionados (como a importância do local da entrevista, em caso de prever a produção de vídeo e/ou captação de áudio). Gestores e repórteres estão cada vez mais conscientes desta necessidade, o que passa, obviamente, pela existência de condições favoráveis de produção a serem oferecidas pela empresa, com a disponibilização do pessoal e dos equipamentos pelo tempo determinado.

Diante de tamanha dedicação exigida, a grande reportagem tem conquistado destaque como o espaço mais propício para a prática multimídia e a experimentação de novos formatos, como nos exemplos de trabalhos não factuais identificados principalmente nas editorias de Economia e Política dos jornais analisados. É no gênero específico da reportagem que tradicionalmente as empresas investem mais tempo e dinheiro e os seus profissionais mais experientes e qualificados. Mas bons exemplos começam, aos poucos, a aparecer também na produção factual. Mesmo que de forma mais modesta, como nas coberturas factuais das editorias de Política identificadas na coleta realizada para esta pesquisa.

Vale observar, ainda, que no jornalismo on-line é real o risco de ocorrer um deslumbramento com os recursos técnicos disponíveis e boa parte da energia da reportagem ser direcionada para a produção de elementos em diferentes mídias com uma preocupação maior com o formato do que com o conteúdo. Um movimento interessante no sentido de qualificar esta produção, no entanto, é contar com um profissional ou até mesmo uma equipe para trabalhar essencialmente o planejamento do conteúdo multimídia, no sentido de estabelecer uma priorização do que deve ser "multimidializado" e de que forma isso deve ser feito, de acordo com experiências anteriores, e como este conteúdo deve ser distribuído pelos diferentes canais existentes. Parte deste trabalho diário é justamente identificar entre as diferentes pautas factuais que surgem logo cedo, quais ou apenas qual (no singular mesmo) 
delas merecem um vídeo ou um infográfico interativo. E quais cumprem seu papel informativo essencialmente com texto e foto, por exemplo. E, para a produção não factual, ajudar a escolher os grandes temas que devem contar com elementos audiovisuais que se complementem ao texto aprofundado e contextualizado, característico da reportagem. Ainda assim, mesmo com a valorização do planejamento no processo de produção multimídia, vale registrar a ressalva de que como cada reportagem tem suas peculiaridades, sempre é possível que a equipe venha a lidar com os imprevistos tão presentes na rotina do jornalismo. Ou seja, acredita-se no equilíbrio, pois assim como não faz sentido que um site de notícias traga a maioria de matérias só com texto e foto, sem explorar os recursos próprios do meio on-line; também não é necessário que cada nova matéria publicada no site apresente uma diversidade de recursos, que quando adotados sem critérios reais podem acabar sendo incorporados sem verdadeiramente contribuírem para a narrativa.

Um modelo de produção inspirado em experiências anteriores bem sucedidas, com indicação de passos a serem seguidos, vai ajudar a manter um padrão multimídia entre as novas reportagens, mas, por outro lado, tal conduta também não pode se transformar na burocratização do ciclo de produção, o que comprometeria uma necessária liberdade para lidar com os já mencionados imprevistos e afetaria até mesmo a postura de abertura à novas ideias ou a experimentações de novos formatos e recursos.

Estas questões passam pelo ponto chave que é a disponibilidade e o interesse da própria empresa jornalística em investir pensando em médio e em longo prazo. Entende-se que quando a preocupação não vai muito além da edição do dia, a organização do pessoal é frágil e improvisada. Mas quando existe uma meta real para longo prazo, no sentido de atrair e manter um público consumidor capaz de rentabilizar um jornalismo profissional nas plataformas digitais, a chance de sucesso tende a ser maior.

As empresas do setor seguirão aprendendo e reaprendendo, corrigindo e inovando na base da experimentação, como vem sendo feito ao longo dos últimos anos, reconhecendo erros próprios e dos concorrentes e tendo a sabedoria e a humildade de modificar os rumos quando necessário. Mas, entre tantas incertezas, é forte o reconhecimento de que o digital é o futuro e, cada vez mais, o próprio presente. $\mathrm{O}$ fato de tantas mudanças ocorrerem sem que as empresas jornalísticas deixem de produzir diariamente torna tudo ainda mais difícil. Mas se por um lado, a correção de rumo pode exigir desacelerar em alguns momentos e gerar alguns atropelos na rotina, após uma efetiva virada de chave, é de se esperar que a velocidade aumente e na direção certa. 


\section{REFERÊNCIAS}

ANDERSON, Chris W.; BELL, Emily; SHIRKY, Clay. Jornalismo pós-industrial: adaptação aos novos tempos. Revista de Jornalismo ESPM, São Paulo, v. 5, p. 30-89, abril-maio-junho de 2013.

CANAVILHAS, J. (Org.). Webjornalismo: 7 caraterísticas que marcam a diferença. Covilhã: LabCom, 2014.

COSTA, Caio Túlio. Um modelo de negócios para o jornalismo digital. Revista de Jornalismo ESPM, São Paulo, v. 9, p. 51-115, abril-maio-junho de 2014.

Folha é o $1^{\circ}$ jornal brasileiro a ter circulação digital maior do que a impressa, publicado por Folha de S. Paulo em 25 de setembro de 2016. Disponível em:

$<$ http://www1.folha.uol.com.br/mercado/2016/09/1816633-folha-e-o-1-jornal-do-pais-a-ter-

circulacao-digital-maior-do-que-a-impressa.shtml?cmpid=comptw $>$. Visitado em setembro de 2016.

Gazeta apresenta seu novo projeto editorial ao mercado, publicado por Gazeta do Povo em 6 de abril de 2017. Disponível em: <http://www.gazetadopovo.com.br/economia/gazeta-apresenta-seu-novoprojeto-editorial-ao-mercado-cq2q3xmwls1i83hjdpamdoz6s>. Visitado em abril de 2017.

HILL, Steve; LASHMAR, Paul. Online journalism: the essential guide. Londres: Sage, 2014.

KRIPPENDORFF, K. Content analysis: an introduction to its methodology. Beverly Hills: Sage, 1980.

LENZI, Alexandre. Inversão de papel: prioridade ao digital, um novo ciclo de inovação para jornais impressos. Florianópolis: Insular, 2018.

LONGHI, Raquel Ritter. O turning point da grande reportagem multimídia. Revista Famecos, Porto Alegre, v. 21, n. 3, p. 897-917, setembro-dezembro de 2014.

NEGREDO, Samuel; SALAVERRÍA, Ramón. Integrated journalism: media convergence and newsroom organization. Barcelona: Editorial Sol 90, 2009.

NOCI, Javier Díaz. La escritura digital: hipertexto y construcción del discurso informativo en el periodismo electrónico. Zarautz: Universidad del País Vasco, 2001.

O Globo, Extra e Expresso se integram em uma redação multimídia, publicado por $\boldsymbol{O}$ Globo em 29 de janeiro de 2017. Disponível em: <http://oglobo.globo.com/brasil/o-globo-extra-expresso-se-integramem-uma-redacao-multimidia-20840004>. Acesso em janeiro de 2017.

Projeto editorial da Folha: Jornalismo profissional é antídoto para notícia falsa e intolerância, publicado por Folha de S. Paulo em 30 de março de 2017. Disponível em:

<http://temas.folha.uol.com.br/projeto-editorial-da-folha/projeto-editorial-2017/introducao.shtml>. Visitado em março de 2017.

SALAVERRÍA, Ramón. Periodismo digital: 25 años de investigación. Artículo de revisión. El profesional de la información, Barcelona: v. 28, n. 1, e280101, 2019, p.1-27. 
Doutor e mestre em Jornalismo pela Universidade Federal de Santa Catarina (UFSC).

Professor de Jornalismo na Universidade do Sul de Santa Catarina (Unisul).

Bolsista Capes de pós-doutorado na Universidade Federal de Mato Grosso do Sul (UFMS).

\section{(요 $(0)$}

Esta obra está licenciado com uma Licença

Creative Commons Atribuição-NãoComercial-CompartilhaIgual 4.0 Internacional 